hope to further establish the utility of this enzyme in $\mathrm{TG}$ structure investigations.

\section{R. G. JENSEN \\ J. SAMPUGNA \\ J. G. QUINN}

Department of Animal In. dustries, University of Connecticut, Storrs, Connecticut

\section{ACKNOWLEDGMENT}

Supported in part by Public Health Service Research Grant AM-02605-08 from the Institute of Arthritis and Metabolic Diseases.

\section{REFERENCES}

T. Alford, I. A., and D. A. Pierce, J. Food Sei. 26, 518 (1961).

2. Alford, J. A., D. A. Pierce and F. G. Suggs, J. Lipid Res. 5, 390 (1964).

3. Brockerhoff, H., J. Lipid Res. 6, 10 (1965).

4. Brockerhoff, H., Lipids 1,162 (1966).

5. de Haas, G. H., L. Sarda and J. Roger, Biochim. Biophys. Acta 106, 638 (1965).

6. Jensen, R. G., J. Sampugna, J. G. Quinn, Dorothy L. Carpenter, T. A. Marks and J. A. Alford, JAOCS 42,1029 (1965).

7. van Deenen, I. L. M., in "Metabolism and Physiological Significance of Lipids," edited by R. M. C. Dawson and D. N. Rhodes, John Wiley \& Sons Ltd. New York, 1964 p. 155.

[Received May 13, 1966]

\title{
A Solved Problem of Triglyceride Analysis
}

Sir: A complete stereospecific analysis of triglyceride mixtures requires a considerable amount of data. However a recent letter in your March issue incorrectly states that "with our present methods this is still an impossible task." We wish to affirm that the difficulties can be overcome with perserverance and the methods now available.

The triglycerides that contain only one type of acid cause no difficulty. Fortunately the triglycerides that contain two different types of acid can often be resolved to a greater extent than the total number of alkene groups in the molecule would indicate (e.g., 18:0-18:0-18:2 is separable from 18:0-18:1-18:1 and 18:0 18:0-18:3 from 18:0-18:1-18:2 on $\mathrm{AgNO}_{3^{-}}$ silicie acid plates). The triglyceride species with only two acids have only 3 possible isomers and are easily analyzed.

The triglycerides that contain three different acids require the most consideration in structure determination. They can be readily elassed into three isomeric pairs which must then be further resolved.

\begin{tabular}{cccc} 
Position & \multicolumn{3}{c}{ Triglycerides } \\
1 & AB & AC & BC \\
2 & BA & CA & CB \\
3 & CC & BB & AA
\end{tabular}

The relative amounts of these triglycerides most probably reflects the availability of the different diglyceride precursors. With no steric selectivity, the esterification of $\mathrm{C}$ at position 3 would be expected to produce $\mathrm{ABC}$ and $\mathrm{BAC}$ in the same relative abundance as the pairs $\mathrm{ABB}$ and $\mathrm{BAB}$ or $\mathrm{ABA}$ and $\mathrm{BAA}$ are produced. The latter sets of triglycerides are isomeric pairs that are easily analyzed and could be used to suggest the $\mathrm{ABC} / \mathrm{BAC}$ ratio.
A fully rigorous strueture proof of the threeacid triglycerides requires only the following steps:

(a) Cleavage of the six-isomer mixture to 1,2- and 2,3-diglycerides by triglyceride lipase.

(b) Isolation and analysis of the 1,2diacylglycerol-3-phosphates produced by diglyceride kinase action as described in Federation Proceedings 25, 521 (1966).

(c) Separation of the three isomeric pairs of phosphatidate derivatives according to their acid content.

$\begin{array}{lll}\mathrm{AB} & \mathrm{AC} & \mathrm{BC} \\ \mathrm{BA} & \mathrm{CA} & \mathrm{CB} \\ \mathrm{PP} & \mathrm{PP} & \mathrm{PP} \\ \mathrm{x} & \mathrm{y} & \mathrm{z}\end{array}$

The relative amounts of $x, y$ and $z$ are indicated by the content at the 3 position of $\mathrm{C}, \mathrm{B}$ and $\mathrm{A}$ respectively.

(d) Phospholipase A cleavage of each pair to determine the $\mathrm{AB} / \mathrm{BA}, \mathrm{AC} / \mathrm{CA}$ and $\mathrm{BC} / \mathrm{CB}$ ratios.

If the results of the unequivocal analysis show that the $A B / B A$ ratio is constant in all the triglyceride species, future analyses could then use the values obtained from the more easily measured diacid triglycerides. We hope these comments will adequately indicate that the difficulties of triglyceride analysis can be overeome.

WILLiam E. M. Lands
Sister P. M. SLAKEY
Department of Biological
Chemistry University of
Miehigan, Ann Arbor,
Michigan

[Received April 28, 1966] 